\title{
$A$ accountability das Organizaçóes Sociais no SUS: uma análise do papel institucional do Conselho Estadual de Saúde em Pernambuco
}

\author{
| ${ }^{1}$ Hélder Freire Pacheco, ${ }^{2}$ Eliane Maria Medeiros Leal, ${ }^{3}$ Garibaldi Dantas Gurgel Júnior, \\ ${ }^{4}$ Francisco de Assis da Silva Santos, ${ }^{5}$ Kátia Rejane de Medeiros I
}

Resumo: Este artigo tem como objetivo analisar a percepção dos integrantes dos órgãos de controles interno e externo da gestáo pública, acerca do papel do Conselho Estadual de Saúde na accountability das Organizações Sociais em Saúde. Trata-se de estudo analítico, com abordagem qualitativa, baseado em entrevistas semiestruturadas, com amostra intencional. Dez atores-chave responsáveis pelos mecanismos dos controles interno e externo do Sistema Único de Saúde (SUS) foram selecionados. Os dados revelaram o papel do Conselho em relação às Organizaçôes Sociais em Saúde, que consiste em fiscalizar a gestão dessas organizaçóes como representantes da sociedade. Agir de forma transparente, bem como viabilizar a prestaçáo de contas das Organizaçôes Sociais com linguagem adequada para os integrantes do Conselho, além da independência política e liberdade para fiscalização das açôes de saúde, são premissas que devem ser atendidas para que o processo de acompanhamento seja mais efetivo e propositivo na visão desses atores institucionais.

> Palavras-chave: conselhos de saúde; políticas de controle social; regulação e fiscalização em saúde; organizações em saúde.

\author{
1 Fundação Oswaldo Cruz. \\ Recife-PE, Brasil (helderfp1989@ \\ gmail.com). \\ ORCID: 0000-0001-7710-2237 \\ 2 Fundação Oswaldo Cruz. \\ Recife-PE, Brasil (eliane.medeiros. \\ leal@gmail.com). \\ ORCID: 0000-0002-6052-6501 \\ ${ }^{3}$ Núcleo de Estudos em Saúde \\ Coletiva, Fundação Oswaldo Cruz. \\ Recife-PE, Brasil (gurgel@cpqam. \\ fiocruz.br). \\ ORCID: 0000-0002-2557-7338 \\ ${ }^{4}$ Universidade Federal de \\ Pernambuco. Caruaru-PE, Brasil \\ (francisco.a.santos@hotmail.com). \\ ORCID: 0000-0002-7082-7092 \\ ${ }^{5}$ Centro de Pesquisas Aggeu \\ Magalhães, Fundação \\ Oswaldo Cruz. Recife-PE, Brasil \\ (kmedeiros@cpqam.fiocruz.br) \\ ORCID: 0000-0002-7518-4137
}

Recebido em: 01/08/2019 Aprovado em: 26/08/2019 Revisado em: 26/02/2020 


\section{Introdução}

As OSS surgiram como um novo modelo de gestão após a reforma do Estado nos anos 90 e, desde então, estão inseridas no SUS, sendo uma delegação da prestação de serviços para o terceiro setor, no qual entidades de direito privado se propóem a desempenhar atividades de interesse público. Em sua forma de atuação, através de contratos de gestáo pública com o Estado, esse modelo necessita de uma sofisticada capacidade de regulação pública para controlar a ação dos novos agentes econômicos, principalmente em relação às suas metas e objetivos determinados em contrato, com o dever de prestar contas dos recursos recebidos e dos atos executados durante o seu processo de gestão (MORAIS; ALBUQUERQUE; OLIVEIRA, 2018).

Com a expansão desse modelo de gestão, torna-se relevante a discussão do exercício da accountability. Trata-se de um termo muito usado na administração pública, embora não haja consenso na sua tradução para a língua portuguesa. Neste artigo, o assumimos como "prestação de contas com transparência das ações dos serviços públicos para a sociedade”, terminologia que ganhou força na sociedade contemporânea diante dos processos de mobilização social para acompanhamento das responsabilidades do poder público na saúde (PINHO; SACRAMENTO, 2009).

No desenvolvimento da accountability das OSS, é imprescindível descrever a importância dos controles interno e externo. O controle interno é exercido por órgãos que estejam dentro da estrutura do poder controlado, enquanto o externo é aquele realizado por órgão que não pertença à estrutura do poder no qual o controle é exercido. Assim, a abertura de um canal de diálogo com os órgãos de fiscalização também permite sanar os problemas, muitas vezes, de forma preventiva, evitando a evolução deles e o consequente prejuízo de tempo e recursos públicos (PILOTTO; JUNQUEIRA, 2017).

A accountability faz parte da governança, já que esta se refere à redefinição e ampliação das formas de relacionamento entre Estado e sociedade ou entre governos, agentes privados e sociedade, tendo como traços distintivos a dimensão relacional e a forte interdependência (entre grupos e organizaçôes) que caracterizam uma dada política. De certa forma, é considerada a descentralização do processo decisório e da ação pública para fora dos limites das instituiçôes formais do Estado (MEDEIROS; CRANTSCHANINOV; SILVA, 2013). 
Todavia, Ballesteros (2012) acrescenta que a accountability está situada na governança de nível superior, denominada metagovernança, a qual exige um pacto interinstitucional e processos acordados entre os poderes formais do Estado, através de um conjunto de atores sociais que fazem parte do complexo regulador público da saúde e que viabilizam o exercício das regras, procedimentos e normas específicas de funcionamento da gestão descentralizada para organizaçóes sociais no SUS. O conselho de saúde é um dos órgãos reguladores das ações do Estado, e a discussão do seu papel fiscalizador está embebida na própria discussão do processo de metagovernança já instituída no setor de saúde no Brasil.

O controle social éu m espaço institucional de governança pública com participação da sociedade civil no SUS. Ele se instituiu no contexto da redemocratização do país, com a abertura de canais de participação entre o Estado brasileiro e a sociedade para tomada de decisão sobre a política de saúde. Os órgãos de controle social formalmente viabilizam o diálogo entre governos, trabalhadores, agentes econômicos privados e sociedade (LIMA; ALBUQUERQUE; SCATENA 2015).

Os principais mecanismos legais para operacionalização desse processo de governança participativa no Brasil são as conferências e os conselhos de saúde. Estes permitem a inserção da sociedade civil organizada no controle direto de políticas, programas e serviços de saúde pública em todo o país. Por razóes diversas, observase que os órgãos de controle social não funcionam em toda a sua plenitude, e isso tem influência direta na qualidade do processo de governança pública, com especial destaque para os problemas da assistência à saúde. Essa situação se exacerba com as reformas guiadas pelo mercado e a inserção de organizaçóes sociais no SUS, em face da complexidade da relação público-privado e suas implicaçôes para a administração pública (ROLIM et al., 2013).

Entendendo que, embora haja inúmeros estudos sobre OSS, na perspectiva da accountability o tema ainda é muito limitado. Isso só corrobora a necessidade de discutir os papéis das múltiplas instâncias que formam o complexo regulador do Estado. Acreditamos que a análise específica do papel do Conselho Estadual de Saúde poderá contribuir para a construção de um resgate de valores e reflexôes sobre a atuação dessa instância de governança. Portanto, o objetivo da pesquisa é analisar a percepção dos integrantes dos controles interno e externo sobre o papel do Conselho Estadual de Saúde (CES) na accountability das Organizaçôes Sociais em Saúde. 


\section{Método}

Trata-se de estudo analítico, com abordagem qualitativa, cuja coleta de dados ocorreu entre setembro de 2015 e abril de 2018. A pesquisa foi realizada no Estado de Pernambuco, e os sujeitos foram constituídos por 10 integrantes ligados a órgãos de controles interno e externo que atuam nos serviços de saúde: dois da Secretaria Estadual de Saúde (SES); cinco do Conselho Estadual de Saúde (CES); um do Tribunal de Contas (TCE); um do Ministério Público (MPE); e um representante da Frente Pernambucana contra a Privatização na Saúde (FPPS). Os critérios de inclusão foram aqueles necessariamente vinculados, direta ou indiretamente, aos mecanismos de controles interno e externo na área de saúde. Para preservar a identidade dos entrevistados, as falas foram identificadas pelas siglas dos órgãos de controle mais um número arábico referente à ordem das entrevistas (Ex.: SES1).

Para análise dos dados primários a partir de entrevistas semiestruturadas, recorreu-se à análise por condensação de significados (KVALE, 1996). Assim, após a obtenção dos dados, foram definidas duas categorias centrais: o Conselho de Saúde e o seu papel de controle e fiscalização da gestão e a representação da sociedade via Conselho de Saúde.

O estudo contempla resultados da pesquisa intitulada Redes assistenciais integradas e Sustentáveis: teoria, prática e possibilidades de inovação na dinâmica interinstitucional da regulação do SUS (REG-SUS), aprovada no Comitê de Ética em Pesquisa do Instituto Aggeu Magalhães sob registro 50906915.0.0000.5190/2016 e financiada pelo edital PROEP-FACEPE 2016.

A pesquisa foi realizada de acordo com a Resolução no 466/12, do Conselho Nacional de Saúde, respeitando-se as integridades física e moral dos participantes. Para o sigilo das informaçóes, foi utilizado o Termo de Consentimento Livre e Esclarecido (TCLE).

\section{Resultados e Discussão}

A leitura das entrevistas permitiu a estruturação dos resultados e respectivas discussóes em relação a dois aspectos: o Conselho de Saúde e seu papel de controle e fiscalização da gestão e a representação da sociedade via Conselho de Saúde. 


\section{O Conselho de Saúde e seu papel de controle e fiscalização da gestão}

O repasse de novos serviços em saúde para as OSS em Pernambuco teve início em 2009, com a inauguração do Hospital Miguel Arraes. A gestão estadual tinha como principais objetivos orientar as açóes estatais para maior eficiência e qualidade dos serviços prestados, com foco na flexibilidade gerencial, como também dar rapidez à operacionalização dos novos hospitais e à ampliação de serviços oferecidos à população. Atualmente, existe contrato de gestão com nove Organizaçôes Sociais de Saúde, que atuam em 11 hospitais, sendo quatro metropolitanos e sete no interior do estado, 15 Unidades de Pronto Atendimento (UPAs) e 10 Unidades Pernambucanas de Atenção Especializada. Com esse grau de extensão, a questão do desenho institucional dos controles deve ser considerada (PACHECO et al., 2016).

No tocante aos processos de controle, o Estado de Pernambuco faz o acompanhamento das atribuiçôes, responsabilidades e obrigaçóes das OSS. Instrumentos são estabelecidos para isso, com foco em diferentes níveis e dimensôes dos controles interno e externo, tais como: o contrato de gestão, renovado anualmente, o relatório financeiro e o relatório de execução e desempenho, com periodicidade mensal. Uma vez estabelecidos os parâmetros, o controle sobre as OSS ocorre a partir do acompanhamento e da avaliaçáo dos resultados obtidos pela entidade que devem ser comparados com o que foi previamente acordado no contrato de gestão. Em relação ao CES, evidenciam-se algumas dificuldades desse processo no contexto da governança do SUS (SANTOS et al., 2015).

$\mathrm{O}$ instrumento da prestação de contas, que deve ser encaminhado pelos órgãos de gestão do estado ao CES, tem como foco informar aos conselheiros todos os pontos pactuados com as OSS e seus resultados. Para tanto, é necessário que esses representantes do CES entendam, em sua totalidade, as informações disponibilizadas de forma que estejam inteligíveis, claras e objetivas. Está claro, nas falas dos representantes do CES, que os papéis de controle e fiscalização da accountability das OSS pertencem também ao CES. Porém, apesar da legitimidade e de o envio dessa documentação ser efetuado, existem entraves estruturais que impedem operacionalmente essa ação.

O controle social tem papel fundamental na fiscalização da execução dos contratos firmados entre o Estado e as entidades parceiras. No entanto, por vezes, a insuficiência de informaçôes ou de transparência na forma como os recursos são utilizados dificulta o exercício desse controle. (CES1) 
Quando havia demandas do conselho para prestação de contas solicitando um relatório mais detalhado sempre vinham coisas muito superficiais, muito resumidas, difícil de compreender, não dá a dimensão do que de fato ocorre, nunca vem no detalhe e na linguagem que era necessário. A prestação de contas não pode ser apenas uma função figurativa. (CES2)

Destaca-se a necessidade do CES de ter acesso a todo o conhecimento relacionado aos temas discutidos, além da garantia de transparência das informaçôes da atuação das OSS. Contudo, por mais que o Conselho seja o espaço máximo deliberativo, onde a sociedade participa de forma representativa, essa função não vem sendo garantida. Na percepção dele, as informaçóes são passadas ainda de forma incompleta e com linguagem não acessível a todos, dificultando o acompanhamento e a deliberação de processos.

Pode-se afirmar que a função accountability no controle social se faz presente na Resolução no 453/12, emitida pelo Conselho Nacional de Saúde, que versa sobre a questão do conteúdo a ser destacado nas prestações de contas. Os principais temas que devem ser abordados são: andamento da agenda de saúde pactuada; relatório de gestão; montante, fonte e forma de aplicação dos recursos; auditorias iniciadas e concluídas no período; oferta e produção de serviços na rede assistencial (BRASIL, 2012).

A Lei Complementar $n^{\circ}$ 141/2012 estabelece que os Conselhos devem avaliar a gestáo do SUS quadrimestralmente e emitir parecer conclusivo a respeito do cumprimento dos dispositivos sobre as contas anuais encaminhadas pelo respectivo gestor federal, estadual, distrital ou municipal. Nesse contexto, confirma-se a importância do Conselho de Saúde como uma das principais instâncias do controle social, além de enfatizar o direito de ter acesso e solicitar qualquer informação necessária (BRASIL, 2012).

No tocante às OSS, a Lei Estadual de no 15.210/13 descreve especificamente o acompanhamento, avaliação e fiscalização dos contratos de gestão das OSS. Também afirma que o relatório anual de prestação de contas das OSS deve ser encaminhado ao Núcleo de Gestão do Poder Executivo, ao Tribunal de Contas do Estado, à Assembleia Legislativa, além do Conselho Estadual de Saúde (PERNAMBUCO, 2013).

Do ponto de vista legal, há o reconhecimento do protagonismo do CES na accountability das OSS. Contudo, Silva, Lima e Teixeira (2015) demonstram que, quanto ao acompanhamento e à fiscalização da execução do contrato de gestão e dos relatórios pelos Conselhos de Saúde, a Lei Federal sobre OS não faz menção a essa 
prestação, nem mesmo cita essa entidade no corpo de seu texto legal. Além disso, as normatizaçôes estaduais e municipais sobre OS pouco incorporam, em seus textos legais, a participação dos Conselhos de Saúde no processo de acompanhamento e fiscalização. Na legislação consultada, 15 estados e 36 municípios não fazem qualquer menção à prestação de contas aos Conselhos de Saúde.

Contudo, ainda existe uma lacuna entre a legalidade e a realidade prática das atividades do conselho no controle das OSS, seja pela baixa transparência, informações com baixo detalhamento e linguagem de difícil compreensão. Violin (2007) destaca também em seu estudo que o processo de fiscalização das OSS ainda tem percalços, como a dificuldade de acesso às informaçôes por parte dos órgãos de controle externo, como os Tribunais de Contas, e, mesmo internamente, pelos órgãos de Controle Social do SUS. Esse autor afirma que, por serem as OSS entidades que recebem recursos públicos, devem garantir transparência e acesso irrestrito e sem burocracia e de forma ágil a qualquer informação solicitada.

O acompanhamento pelo Poder Público contratante é obrigatoriedade legal. É isso que condiciona as irregularidades à ação de accountability pelo controle externo. Operacionalmente, o acompanhamento se concretiza por visitaçôes periódicas não contínuas e/ou captação de dados dos próprios contratantes. Esse contexto proporciona a conivência com as informaçóes fornecidas e um risco de baixa acurácia avaliativa sobre eficiência e efetividade dos serviços de saúde ofertados. A possibilidade de baixa accountability (controle, fiscalização e avaliação pelos atores políticos) vai de encontro à potencialidade teórica do modelo gerencialista, que pressupóe uma alta capacidade regulatória do Estado (SOUZA et al., 2018).

De forma geral, as informaçôes sobre as OSS, como indicadores, metas de desempenho e resultados presentes nos contratos de gestão, não estão disponíveis em sistemas de informação do SUS, apenas no Diário Oficial - veículo de comunicação com extrema dificuldade de acesso e, ao mesmo tempo, até pouco conhecido pela população em geral. O site da SES possui informaçóes e instrumentos colocados de forma incompleta, sendo publicadas apenas as OSS que podem atuar em Pernambuco, os respectivos equipamentos cedidos e os contratos de gestão firmados. Quanto aos relatórios anuais de prestação de contas, apenas de alguns serviços foram publicados até 2014, o que vai contra a Lei 15.210/13, ao afirmar que a SES deverá disponibilizar anualmente, em seu sítio eletrônico, todos 
os contratos de gestão celebrados e os respectivos relatórios de gestão, sem prejuízo das publicações no Diário Oficial do Estado.

A necessidade de melhoria no conteúdo dos relatórios é notória. É uma premissa para que o exercício do controle seja efetuado com o mínimo de eficiência e possibilitando uma aproximação maior entre os governos e a sociedade. Segundo Borges (2014), a prestação de contas, em determinados casos, não consegue ser efetiva por conta da qualidade das informaçóes que são encaminhadas às instituiçôes de controle.

Em relação ao papel técnico do Conselho de Saúde, é necessário observar o critério da compreensibilidade da informação posta à disposição dos cidadãos. Segundo Rodrigues (2014), qualquer informação precisa apresentar a clareza de conteúdo, de elementos de sua composição, do motivo, da finalidade, a fim de permitir o seu controle. A informação deve ser abrangente, atual, ser divulgada desde a sua fonte original e sem alteraçóes. Os resultados trazidos por isso concedem legitimidade, validade e eficácia aos diferentes níveis e mecanismos de controle e fiscalização institucional.

A gestão das OSS não tem nenhum sistema específico. É realizada, basicamente, através de relatórios em Excel com expressão de inúmeros valores e com o aporte cada vez maior de recursos para esse modelo no Estado, dificultando ainda mais a análise. O governo de Pernambuco, nos últimos anos, elevou os gastos, tanto com os hospitais com gestão por OSS quanto com os de gestão pública. Porém, o percentual de aumento é bem maior para a gestão por OSS do que com a gestão pública. A diferença dos gastos totais chega a $\mathrm{R}$ \$262,8 milhóes para as OSS. Isso demonstra a importância do CES em demandar tempo para a análise desses dados (XIMENES; SCHMALLER; BEZERRA, 2018).

Não há uma receita única e certa para que as organizaçóes públicas propiciem à sociedade as informaçôes desejadas a cada cidadão. Mas é necessário ter em mente que o controle social não se faz apenas a partir da abundância de informaçôes, mas também do entendimento que o cidadão dela faz.

Atualmente, apesar da tentativa de promoção de maior transparência, há uma reclamação frequente dos conselheiros para que se possam discutir os problemas e indicar correçôes cabíveis à gestão, mesmo quando eles apresentam níveis de desempenho inaceitáveis. 


\begin{abstract}
A Gestão sempre tem feito um processo muito lento de dar as respostas e quando essa resposta vem, vem de uma forma muito superficial, numa forma de apresentação que eu já questionei que sempre tem uma estratégia de ter apresentaçôes longas para que o debate seja menor. (CES3)

Acho que temos que debater mais. Agora, não é o governo falando uma hora e a gente questionando com dois minutos; então o pessoal da gestâo vem, apresenta os dados por uma hora, mas quando vai a discussão para o conselho, fica pouquíssimo tempo para discutirmos. (CES4)
\end{abstract}

A partir das entrevistas, é importante destacar a restrição do diálogo quanto à prestação de contas das OSS, já que isso impede que o Conselho de Saúde tenha confiança no processo decisório - aprovar ou não a prestação de contas -, o que impacta de forma negativa na gestão da saúde pública. Não obstante, como destacado por Cotta et al. (2010), isso acaba por criar um hiato na relação entre Estado e sociedade, onde pode ocorrer um enfraquecimento da ideia de democracia e, consequentemente, uma inserção menos contundente da accountability na saúde, especificamente no caso das OSS.

Essa mesma situação é evidenciada em estudo realizado no CES do Rio de Janeiro, no qual alguns conselheiros relatam que, enquanto espaço decisório, passam a cumprir um papel burocrático, pois os temas relevantes ou não são pautados ou, quando são, as reuniốes são desmontadas através da pactuação para a não obtenção do quórum. Além disso, a gestão concentra a decisão e não pauta a discussão no pleno, ficando este com a função da votação burocrática para não obstruir os processos que demandam sua aprovação (FERREIRA, 2013).

Zambon (2011) afirma que as demandas levadas pela gestão aos Conselhos de Saúde são mais informativas, no sentido de esclarecer o que está sendo realizado pelo Poder Público, de aprovação de plano e relatório de gestão. A utilização da reunião do Conselho como espaço informativo vem ao encontro da constatação decorrente desse estudo desenvolvido sobre o Conselho Nacional de Saúde, em que 39\% do tempo foram despendidos com questóes informativas.

A Resoluçáo 453/12, que aprova as diretrizes para o funcionamento dos conselhos, descreve que o Pleno do Conselho de Saúde deverá manifestar-se por meio de resoluçóes, recomendaçôes, moçôes e outros atos deliberativos. Em relação às resoluçóes, estas serão obrigatoriamente homologadas pelo chefe do poder constituído em cada esfera de governo, em um prazo de 30 (trinta) dias, dando- 
lhes publicidade oficial. Decorrido o prazo mencionado e não sendo homologada a resolução, nem enviada justificativa pelo gestor ao Conselho de Saúde com proposta de alteração ou rejeição a ser apreciada na reunião seguinte, as entidades que integram o Conselho de Saúde podem buscar a validação das resoluções, recorrendo à Justiça e ao Ministério Público, quando necessário.

Fica demonstrado que o instrumento da resolução, do ponto de vista legal e prático, é o mais eficaz para dirimir dúvidas, solicitar informaçôes e até mesmo apontar incongruências da gestão. Outro destaque é que o gestor tem até 30 (trinta) dias para, além da garantia de publicidade, dar uma resposta ao que foi solicitado. As atas são instrumento apenas de prestação de contas das atividades do Conselho, ficando tâo somente para sua conferência interna.

Vale lembrar que os mecanismos que garantem a atuação do Conselho de Saúde, perante a fiscalização das OSS, não são capazes de garantir plenamente a accountability nestas, pois seus instrumentos não funcionam como um meio de punição, mas sim como garantia no seu aspecto legal de contribuir para a correção de falhas nos relatórios de prestaçóes de contas e, consequentemente, o alcance dos resultados desejados.

Portanto, é interessante a articulação dos conselhos de saúde com outras estruturas do controle externo, como o Tribunal de Contas e Ministério Público, que vêm avançando no processo de controle e fiscalização das contas das OSS, fazendo com que a Gestão Pública da Saúde adote uma postura cada vez mais accountable (Bernardo, 2009). Assim, é primordial o estabelecimento de vínculos entre a sociedade e os órgáos controladores, de modo a existir compartilhamento de informaçôes, canalização adequada das demandas sociais e, sobretudo, auxílio técnico na análise das condutas.

\section{A representação da sociedade via Conselho de Saúde}

Um dos passos importantes para a edificação do controle social do SUS é respeitar o papel político do Conselho de Saúde. É necessário entender que exercer esse papel é um direito do cidadáo, permeado pelo acompanhamento da gestão pública, de participar das diretrizes das políticas públicas, organizar-se politicamente para definir suas prioridades e principais demandas e, por fim, ter acesso aos resultados das açôes governamentais. 
Segundo Oliveira e Pinheiro (2010), para que o papel político funcione, a conscientização da sociedade é fundamental, e cabe ao poder público criar instrumentos de participação, amplamente divulgados e postos ao alcance de todos. Enquanto o controle social não fizer parte da cultura do povo, ele não pode substituir os controles formais hoje existentes.

As falas, a seguir, de representantes de estruturas do controle externo, como TCE e MPE, salientam a importância e a relevância do papel político do Conselho de Saúde como instância na fiscalização das OSS e que, inclusive, essa função deve ser buscada com prioridade quanto ao papel técnico que venham a exercer.

O mais importante que eu vejo do conselho é o seu papel político de pressão; é a capacidade de tensionar. Eu náo acho que o conselho deveria se preocupar muito em exercer um papel técnico de controle. Eu vejo o conselho com o potencial de exercer um papel político de pressionar o Poder Executivo, as organizaçôes sociais e os órgãos de controle. (TCE1)

Muito conselheiros não têm uma capacitação, digamos, de entender uma contabilidade, mas eu acho desnecessário também isso, eu acho que o conselho tem que entender é se a política está caminhando num sentido ou no outro. Para fazer papel técnico, já tem os tribunais de contas, já tem os outros órgáos, inclusive podemos trabalhar em parceria, e esses órgãos vão nos ajudar a fazer as interpretaçôes pra gente perceber para que lado está caminhando a política. (MPE1)

Os governos e, especificamente, os gestores da saúde, agem na maioria das vezes por pressão e cobrança da sociedade, quando esta se mobiliza em defesa da saúde, como direito de todos e dever do Estado. E no tocante às OSS, o controle social é um movimento que ainda tem muito a avançar na busca de um processo democrático mais sólido e impulsionador do estreitamento da relação entre sociedade e governo. Isso será fundamental para a sociedade ter acesso a informaçôes sobre a forma como a gestão conduz as OSS por meio da prestação de contas - considerada aqui como instrumento de accountability -, como também ter o entendimento das informaçôes contidas nessa importante ferramenta, através de uma linguagem acessível à população em geral.

Outro ponto a ser abordado é a verificação de um eventual espaço para a accountability na administraçấo pública brasileira, mais especificamente dentro dos Conselhos de Saúde - considerados aqui como arenas públicas do exercício democrático. Contudo, as práticas de accountability ainda precisam de um alicerce democrático mais sólido para que seja possível explorar os benefícios desse instrumento em um nível mais efetivo. E como buscar esse alicerce democrático, distante das 
cooptaçôes e dos fisiologismos? Dar respostas para o referido questionamento não é uma tarefa simples. A seguir, as falas dos representantes do controle social revelam a percepção sobre a dificuldade de exercer o papel político diante dessa questão.

\footnotetext{
Estar ali pressionando a gestão no aspecto mais político do que técnico é positivo, mas em relação às OSS, ultimamente as medidas têm sido mais nesse sentido de a gestão não ser incomodada, ou seja, quanto mais livre melhor e, com a manipulaçáo de certos usuários que vejo, na realidade, a pressão na gestão sobre isso é sempre desmontada. (CES5)

O conselho precisa ter uma militância forte como oposição, são atores, são lideranças que precisam reagir, exercer um papel político de questionar, exigir o debate, mas boa parte é ligada ao governo, e de certa forma amarra esses conselheiros, com mais dificuldade de ser crítico, não pode expor muito o governo. Então muitas das coisas são abafadas. (FPPS1)
}

Não é de hoje que se faz o questionamento quanto ao fisiologismo e o nível de cooptação dos Conselhos de Saúde e outros espaços do controle social pela gestáo, comprometendo bastante a ascensão do Conselho como um espaço político. Assim, muitas vezes, por mais que o Conselho tenha informação, ainda há muitos conselheiros que náo entendem o seu papel, enquanto representativo, de participar e entender uma política pública, além de atuar para que ela funcione.

Santos (2004) indica que é frequente as vagas dos usuários do SUS serem ocupadas por parentes de pessoas do Legislativo ou do Executivo, com a intenção de evitar possíveis conflitos entre os interesses da gestão. Nessa situação, a representatividade dos usuários fica prejudicada. O processo de representação também é tolhido quando o conselheiro não mantém os seus vínculos com a base, seja no processo de repassar as informaçóes discutidas no pleno do conselho, seja na articulaçáo de posiçóes com suas bases, previamente sobre aquilo que será debatido e decidido nas reuniōes plenárias.

A questão da democracia interna nas práticas dos conselhos tem sido um tema que começa a ser observado por alguns estudiosos. Nesse sentido, vem sendo destacada a perda do caráter da diversidade e do poder da representação nesses espaços. Isso se dá pela formação de uma "elite de referência", ou seja, pelo exercício de um poder maior de um grupo sobre o conjunto de atores que, geralmente, apresenta maior capacitação técnica ou política, maior perfil socioeconômico e que consegue ter maior poder de influência em relação a outras representaçôes (ABRANCHES, 2004).

Vieira (2010) ressalta que há dois projetos de participação social, sendo um neoliberal e o outro, político. A participação social tem o papel de contribuir na formulação de políticas públicas de atores historicamente excluídos. Contudo, o 
projeto neoliberal dá outro significado ao restringir a participação da sociedade à implementação e execução de açôes e programas vinculados às políticas públicas. No contexto das diferenças, o projeto político tem o objetivo de trazer a sociedade às arenas de participação e à prática da política, enquanto o neoliberal ressignifica ao extrair o caráter político da participação, transformando-a em "participação voluntária”, perdendo, dessa forma, a oportunidade do debate político.

Desde a definição pela Constituição Federal, a qual afirma que "todo o poder emana do povo, que o exerce por meio de representantes eleitos ou diretamente", inúmeros espaços e instrumentos de controle social proliferaram para permitir o exercício da democracia participativa, seja por meio de conselhos, conferências, audiências e consultas públicas, mesas de negociação, ouvidorias. A ouvidoria em saúde é um exemplo de controle do funcionamento da administração pública, denunciando eventuais falhas e difundindo os princípios de justiça entre os cidadãos. Também vale citar a Lei de Acesso à Informação, a qual regulamenta o direito constitucional de acesso às informaçóes públicas. Em suma, são avanços no campo da gestão democrática (COSTA; VIEIRA, 2013). Entretanto, é por meio dos Conselhos de Saúde que a sociedade mais deve expressar suas opinióes e seus interesses e tem a oportunidade de acompanhar e fiscalizar as açóes de saúde nos três níveis de governo. No Brasil, além do Conselho Nacional de Saúde, soma-se um total de 27 Conselhos Estaduais de Saúde e mais 5.500 Conselhos Municipais. Embora possa afirmar-se que a institucionalização formal dos conselhos é efetiva, muitos atuam precariamente em função justamente de práticas disfuncionais, como cooptação política, corporativismo e clientelismo, que influenciam de forma negativa a possibilidade de relaçóes horizontalizadas entre Estado e sociedade (PEREIRA NETO, 2012).

Por outro lado, num contexto de conflitos derivados de posturas ideológicas e corporativas, os gestores estaduais referem-se a como as posiçóes de uma minoria acabam desvirtuando qualquer função técnica ou política inerente ao Conselho Estadual de Saúde.

Qualquer discussão de OSS, principalmente nos questionamentos sobre a transparência, ela entrou na seara ideológica e aí quando entra nessa seara, as palavras são jogadas ao vento, é discurso mais panfletário, e isso faz com que certas pessoas não queiram ouvir o que a gente está querendo dizer, sem sequer ler o que nós temos demonstrado. Entáo, temos que ter muito cuidado para não entrar nessa questão ideológica, que, por ser um governo de determinada posição, o modelo deve ser tal. (SES1) 


\begin{abstract}
Muitos conselheiros não vão de peito aberto, para ouvir, para discutir e saber o que o outro está dizendo, falar, ser ouvido e ouvir, não querem sair do ideológico, e o SUS, a gente tem que blindar, que é o nosso maior patrimônio. E a gente precisa blindar de algumas questôes, assim, político-partidária, de alguns sindicatos que nesse momento também se aproveitam. (SES2)
\end{abstract}

Há uma linha de concordância de que a discussão ideológica prejudica a principal função do Conselho de Saúde, que é discutir a política pública, fiscalizá-la e deliberála. Segundo Tatagiba e Teixeira (2007), a presença de tensão política no interior dos Conselhos de Saúde tem mostrado que este é mais um espaço das disputas partidárias da política tradicional, ultrapassando até questóes ideológicas, já que subordina o estabelecimento de acordos e articulaçóes necessárias à construção pactuada das políticas com finalidades eleitorais dos diferentes grupos em cada conjuntura específica. Os conflitos no Conselho, muitas vezes, nem estão relacionados às disputas de diferentes concepçôes, mas à disputa de poder político no sentido mais estreito, pela conquista ou manutenção das maiorias eleitorais, sendo um conselho ocupado por conselheiros em íntima aliança com os governantes. De um ou de outro lado, esses conselheiros são defensores das posiçóes do governo.

Além disso, há nos conselhos a tendência ao favorecimento da postura do veto, comprometendo o debate e a negociação sob a ótica dos interesses da coletividade. Cortes (2009) afirma que as dificuldades aumentam ainda mais quando o Poder Executivo, ao verificar a permanência dessa postura, passa a desconsiderar as "deliberaçôes" do Conselho e a deslocar suas decisões para outras instituições, em especial às comissóes intergestoras, seja a tripartite, bipartites e regionais, desconsiderando, em diversos momentos, as decisôes tomadas pelo âmbito do controle social.

Zambon (2013) ratifica que a visão centralizadora com o não reconhecimento do papel constitucional atribuído ao Conselho de Saúde revela evidente abuso de autoridade, característico de práticas autoritárias, principalmente sobre os usuários, denunciando a ausência de ética nas relaçôes de dominação, o que "solapa qualquer possibilidade de efetivação" (p.3) do controle social. Reconhecer-se como a voz da população poderia estar relacionado com o conceito de legitimidade, representando ideias de um grupo ou de toda a sociedade.

No outro estudo desenvolvido acerca de conselhos locais de saúde, revela-se a baixa cultura participativa no país, que deve ser compreendida para que se encontrem 
estratégias possíveis para minimizá-la, visto que a simples existência de espaços dialógicos, tais como os Conselhos, é insuficiente para reverter um consolidado histórico de autoritarismo. Os conselhos devem se tornar espaços onde os cidadãos veem suas ideias, sobre a saúde, materializadas. (JEROME, 2018).

A democracia, ao mesmo tempo em que não pode ser delegada, deve ser cada vez mais representativa e participativa. Além disso, nesses espaços, deve-se garantir diversidade dos membros, ter critérios transparentes para escolhê-los, rotatividade e publicidade dos seus atos. Há necessidade de mais vozes, e vozes qualificadas, que façam com que as demandas desses sujeitos sejam expressas e ouvidas.

\section{Consideraçóes finais}

A opção pelo tema do controle social da accountability nas Organizaçôes Sociais em Saúde mostrou-se relevante enquanto mote para o fortalecimento do papel dos Conselhos de Saúde, no processo já institucionalizado legalmente em todo o país. Apesar de este estudo ter sido centrado em Pernambuco, é possível encontrar pontos importantes que são úteis em outros contextos nacionais, onde haja dificuldades para se construir um controle social empoderado e forte.

Os Conselhos de Saúde, como espaços de poder, conflito e negociação, apresentam avanços consideráveis no exercício do controle social e na ampliação da cidadania. Entretanto, enfrentam dificuldades, como a burocratização das suas instâncias para o mero cumprimento de exigências legais. O controle social e seus espaços constituídos têm sido entendidos pelos conselheiros como fundamentais no SUS. Porém, é necessária a compreensão da dimensão que ocupa, visando ao aperfeiçoamento de seu exercício.

A forma incompleta, e muitas vezes incompreensível, dos relatórios de prestação de contas e o pouco tempo de discussão dos relatórios desses documentos entre os representantes do Conselho e o Estado possibilitam pouco diálogo e dificultam a qualidade da fiscalização e da cobrança. Os Conselhos de Saúde devem ter a clareza da utilização de ferramentas de controle de forma sistemática, buscando integração com outros atores do controle externo, como o TCE e MPE, que já vêm executando há mais tempo o processo de fiscalização das OSS.

O Conselho de Saúde não deve sofrer qualquer forma de cerceamento no campo das ideias e das propostas que incitam o debate público em relação a seu processo 
de fiscalização. Isso compromete bastante a sua efetividade como instância de governança na realização do debate das políticas de saúde e de atuação para que elas aconteçam. A função de representação deve ser pautada pelo compromisso, independência crítica e liberdade na formulação e fiscalização das políticas públicas. Portanto, a falta de clareza nas definições jurídicas e legais e sistemas de informação complicados e pouco transparentes - além da magnitude dos interesses múltiplos e conflitantes, diretamente envolvidos com o advento dos novos modelos de gestão da saúde - figuram como elementos que precisam ser mais explorados em pesquisas futuras. Nesse contexto, levam-se em consideração, sobretudo, as relações entre os órgãos de controle tradicionais do Estado e o controle social do SUS na perspectiva da accountability dessas organizaçóes sociais que fazem gestão de unidades de saúde.

Essa situação complexa é um novo fenômeno político institucional, ainda carente de investigação científica, desde a implementação das reformas de segunda geração do Estado, colocadas em prática no setor público de saúde e que expressam a falta de condiçôes ideais do próprio Estado ser controlado pela sociedade. ${ }^{1}$

\section{Referências}

ABRANCHES, M. A. S. (Org.) A capacidade dos conselhos setoriais em influenciar politicas públicas: realidade ou mito, Rio de Janeiro: Revan, 2004.

BALLESTEROS, P. R. Governança democrática: por uma nova perspectiva de análise e construção das politicas de segurança pública no Brasil. Dissertação (Mestrado) - Fundação Getúlio Vargas, Escola de Administração de Empresas de São Paulo. São Paulo: FGV, 2012.

BERNARDO, R. A. Public Services Agreements as a tool of performance accountability: the UK case. Dissertação (Mestrado em Políticas Públicas e Administração) - London School of Economics and Political Science, Londres, 2009.

BORGES, T. J. G. Práticas de Accountability na Administração Pública Brasileira: existe espaço para este Instrumento na Saúde Pública Tupiniquim via Conselhos de Saúde? In: Encontro da ANPAD - EnANPAD. XXXVIII. Rio de Janeiro, 2014.

BRASIL. Ministério da Saúde. Conselho Nacional de Saúde. Resolução n. 453, de 10 de maio de 2012. Aprova as seguintes diretrizes para instituição, reformulação, reestruturação e funcionamento dos Conselhos de Saúde. Brasília, 2012.

Presidência da República. Casa Civil. Subchefia para Assuntos Jurídicos. Lei

Complementar $n^{\circ} 141$, de 13 de janeiro de 2012: Regulamenta o $\$ 3^{\circ}$ do art. 198 da Constituiçáo Federal. Brasília, 2012. 
CORTES, S. V. (Org.). Conselho Nacional de Saúde: histórico, papel institucional e atores estatais e societais. Rio de Janeiro: Fiocruz, 2009.

COSTA, A. M.; VIEIRA, N.A. Participação e controle social em saúde. In: FUNDAÇÃO OSWALDO CRUZ. A saúde no Brasil em 2030. Prospecção estratégica do sistema de saúde brasileiro: organização e gestão do sistema de saúde [online]. Rio de Janeiro: Fiocruz/Ipea/Ministério da Saúde/Secretaria de Assuntos Estratégicos da Presidência da República, 2013. V. 3. p. 237-271.

COTTA, M. M. et al. Controle social no Sistema Único de Saúde: subsídios para construção de competências dos conselheiros de saúde. Ciência \& Saúde Coletiva, Rio de Janeiro, v. 2, n. 3, p. 24-46, 2010.

FERREIRA, S. C. C. Política pública de saúde: análise da agenda do estado do Rio de Janeiro. 2013. Tese (Doutorado em Saúde Pública) - Universidade do Estado do Rio de Janeiro, Faculdade de Serviço Social, Rio de Janeiro, 2013.

JEROME, J. S. Governança participativa no âmbito dos conselhos de saúde locais: entrevistas com seis presidentes de conselhos de saúde locais no Nordeste do Brasil. Saúde e sociedade, São Paulo, v. 27, n. 3, p. 740-753, 2018.

KVALE, S. Interviews: An introduction to qualitative research interviewing. London: Sage Publications, 1996.

LIMA, L. D.; ALBUQUERQUE, M. V.; SCATENA, J. H. G. Quem governa e como se governam as regióes e redes de atenção à saúde no Brasil? Contribuiçóes para o estudo da governança regional na saúde. Novos Caminhos, n. 8, 2015.

MEDEIROS, A. K.; CRANTSCHANINOV, T. I; SILVA, F. C. Estudos sobre accountability no Brasil: meta-análise de periódicos Brasileiros das áreas de administração, administração pública, ciência política e ciências sociais. Administração Pública, Rio de Janeiro, v. 47, n. 3, p. 745-775, 2013. MORAIS, H. M. M.; ALBUQUERQUE, M. S. V.; OLIVEIRA, R. S. Organizações Sociais da Saúde: uma expressão fenomênica da privatização da saúde no Brasil. Cadernos de Saúde Pública, Rio de Janeiro, v. 34, n. 1, p. 19-49, 2018.

OLIVEIRA, L. C.; PINHEIRO, R. A participação nos conselhos de saúde e sua interface com a cultura política. Ciência \& Saúde Coletiva, Rio de Janeiro, v. 15, n. 5, p. 33-58, 2010.

PACHECO, H. F. et al. Organizaçóes sociais como modelo de gestão da assistência à saúde em Pernambuco, Brasil: percepção de gestores. Interface, Botucatu, v. 20, n. 1, p. 585-595, 2016.

PEREIRA NETO, A. F. (Org.). Conselhos de favores: controle social na saúde - a voz dos seus atores. Rio de Janeiro: Garamond, 2012.

PERNAMBUCO. Governo do Estado. Lei Estadual no 15.210, de 19 de dezembro de 2013. Dispóe sobre as organizaçóes sociais de saúde - OSS, no âmbito do Estado de Pernambuco. Diário Oficial do Estado, Recife, 2013. 
PILOTTO, B. S.; JUNQUEIRA, V. Organizações Sociais do setor de saúde no estado de São Paulo: avanços e limites do controle externo. Serviço social \& sociedade, v. 1, p. 547-563, 2017.

PINHO, J. A. G.; SACRAMENTO, A. R. S. Accountability: já podemos traduzi-la para o português? Administração Pública, Rio de Janeiro, v. 43, n. 6, p. 1343-1368, 2009.

RODRIGUES, J. G. Publicidade, transparência e abertura na Administração Pública. Revista de Direito Administrativo, Rio de Janeiro v. 266, p. 89-1023, 2014.

ROLIM L. B.; CRUZ, R. S. B.; SAMPAIO, K. J. A. Participação popular e o controle social como diretriz do SUS: uma revisão narrativa. Saúde em Debate, Rio de Janeiro, v. 37, n. 96, p. 139-147, 2013.

SANTOS, M. R. M. (Org.). A representação social no contexto da participação institucionalizada. O caso dos conselhos municipais do Rio de Janeiro. Rio de Janeiro: Revan, 2004

SANTOS, F. A. S. et al. A definição de prioridade de investimento em saúde: uma análise a partir da participação dos atores na tomada de decisão. Physis, Rio de Janeiro, v. 25, n. 4, p. 1079-1094, 2015.

SILVA, V. M.; LIMA, S. M. L.; TEIXEIRA, M. Organizaçôes Sociais e Fundaçóes Estatais de Direito Privado no Sistema Único de Saúde: relação entre o público e o privado e mecanismos de controle social. Saúde em Debate, Rio de Janeiro, v. 39, n. 2, p. 145-159, 2015.

SOUZA, J. S. et al. Gestão hospitalar no SUS: correlaçôes entre rede de atençáo e capacidade de gestão dos serviços. Saúde para debate, Rio de Janeiro, v. 58, n. 2, p. 46-57, 2018.

TATAGIBA, L.; TEIXEIRA, A. C. C. (Org.). O papel do CMS na Política de Saúde em São Paulo. São Paulo: Pólis, 2007.

VIEIRA, N. A. A. A representação dos usuários no Conselho Municipal de Saúde de Campinas. 2010. Dissertação (Mestrado em Ciência Política) - Universidade Estadual de Campinas, Campinas, 2010.

VIOLIN, T. C. Da administração pública patrimonialista à administração pública gerencial e a burocracia. Administração Constitucional, Curitiba, v. 7, n. 30, p. 225-47, 2007.

XIMENES, A. F.; SCHMALLER, V. P.; BEZERRA, A. F. B. Alocação de recursos do fundo público para organizaçóes sociais da saúde. Sociedade em debate, Pelotas, v. 24, n. 3, p. 113$128,2018$.

ZAMBON, V. D.; OGATA, M. N. Configuraçóes dos Conselhos Municipais de Saúde de uma região do Estado de São Paulo. Revista da Escola de Enfermagem, São Paulo, v. 45, n. 4, p. 890-897, 2011.

ZAMBON, V. D.; OGATA, M. N. Controle Social no Sistema Único de Saúde: o que pensam os conselheiros municipais de saúde. Revista Brasileira de Enfermagem, Brasília, v. 66, n. 6, p. 921-927, 2013. 


\section{Nota}

${ }^{1}$ H. F. Pacheco foi responsável pela concepção, planejamento e interpretação dos dados. E. M. M. Leal responsabilizou-se pela interpretação dos dados e composição na discussão. G. D. Gurgel Júnior atuou na análise crítica do conteúdo. F. A. S. Santos participou da elaboração do artigo e da interpretação dos dados. K. R. de Medeiros participou da análise na discussão e redação final do artigo. 


\section{Abstract}

The Social Organizations' accountability in SUS: an analysis of the institutional role of the State Health Council in Pernambuco This article aims to analyze the perception of the members of the internal and external control organs of public management, about the role of the State Health Council in the accountability of the Social Organizations in Health. This is an analytical study with a qualitative approach, based on semi-structured interviews, with intentional sample. Ten key actors responsible for the internal and external control mechanisms of the Unified Health System [SUS] were selected. Data revealed the role of the State Health Council in relation to the Social Organizations, which is to oversee the management of these organizations as a representative of society. The need to act in a transparent manner and to enable the provision of Social Organizations in Health's records with adequate language for the members of the Council, besides political independence and freedom to supervise health actions are premises that must be met in order for the monitoring process to be more effective and proactive in the eyes of these institutional actors.

Keywords: Health Council; social control policies; health regulation and surveillance; health organizations. 